anomalous cosm ic ray component - the high flux of low ( $\leqslant 30 \mathrm{MeV} /$ nucleon) energy $\mathrm{He}, \mathrm{O}, \mathrm{N}$ and $\mathrm{Ne}-$ and the implications of its eventual solution for the diffusive modulation theory. In the discussion of propagation theory he again outlines a broadly based objective examination of the challenges to the same theory, especially at the low energies. Fisk correctly emphasizes the need for probing the off-ecliptic solar wind for definitive observations (vis-à-vis the modulation theories) of galactic particle entry into the solar system and the implications for astrophysical plasmas.

An exceptionally rigorous theoretical review of hydromagnetic waves and turbulence is presented by A. Barnes in the fifth chapter intended, clearly, for only the experienced plasma physicist. Sections 3 and 4 provide a valuable, unified treatment of MHD waves and the kinetic theories of hydromagnetic waves. Serious workers will find it very useful to review the bases upon which MHD theory is correct and when it can be misleading. The author correctly concludes that hydromagnetic wave theory will be significantly advanced by the numerical simulation of large amplitude waves. Barnes' most important contribution is probably his review of several points which are important for understanding some microscale $(\leqslant 0.01$ AG) solar wind phenomena: (1) interplanetary 'turbulence' probably consists of slowly damped, often sharply crested, solar-originated, nonlinear Alfven waves and (2) magnetoacoustic waves probably damp close to the sun (thereby transferring some momentum and energy close to the solar wind's source) but are probably regenerated farther out as a result of solar disturbances. The necessity of understanding the in situ observations before astrophysical observations (such as 'wisps' of synchrotron emission in the Crab nebula) can ever have a chance of being understood is again made with justifiable emphasis.

The final chapter by W. C. Feldman is devoted to kinetic processes in the solar wind as found by his laboratory's 'touching' this readily accessible example of a cosmic plasma via instruments on a variety of spacecraft. The author succinctly summarizes some of the detailed electron and proton velocity distributions at $1 \mathrm{AU}$ and discusses the regulation of solar wind heat flux in terms of the bulk motion of the hot electrons relative to the plasma frame of reference. He demonstrates the usefulness of comparing microscale data analyses with existing theories of instabilities which involve the Alfven, magnetosonic, and whistler wave modes. The importance of non-Maxwellian particle velocity distributions and their role in kinetic plasma processes is emphasized. Several additional examples of plasma physics, type III radio emission, in situ particle acceleration, and ion beam regulation, are provided to drive home the fact that the study of kinetic plasma processes in the solar wind not only has its own intrinsic scientific interest, but is applicable to problems in laboratory fusion and astrophysics. However, unlike the previous author's approach, there was no discussion of the kinetic processes within the broader (admittedly lower magnification) macroscale context of steady and unsteady fluid processes on a global scale. Nevertheless, a strong case is made for future studies which should involve three-dimensional velocity distributions, both close to the sun and over the poles, of electrons, protons, and the heavierions.

The publisher and editors are to be commended for providing an excellent subject and author index, a feat which far outweighs the typographical errors missed in galley proofing. The book is highly recommended, not only for active workers in the field described in its title but also for the astrophysical community.

M. Dryer is with the Space Environment Laboratory, NOAA Research Laboratories, Boulder, Colorado.

\title{
AGU
}

\section{James B. Macelwane Award: Citation and Acceptance of Lawrence Grossman}

\section{Citation}

It is a pleasure to present Lawrence Grossman for the Macelwane Award. This occasion is particularly auspicious since the AGU meeting is held here in Toronto, Canada, where Larry was born and raised. As a young man he worked in a mining company plant in northern Manitoba, fixing railroad ties and then doing copper analyses of drill cores in their assay office. On careful investigation I found that he also had some criminal connections with the nearby offices of the Ontario Provincial Police, which was located a short distance from here along the waterfront. Fortunately, this turned out to be on the legal side and not the seamy side. It appears that Larry had directed his natural investigative skills toward doing mineral and chemical analyses of soils scraped from the shoes of suspected criminals. Larry Grossman has not changed direc- tions-just subjects. His investigative skills are now directed toward rocks and soils scraped from the sole of the early solar system. The solar nebula is a place for which scientific proofs are often circumstantial, there being few witnesses to the crimes of creation.

The past decade has seen major advances in understanding the connection between the formation and evolution of planets, the formation and evolution of the very small objects which formed before the planets, and the precursors of this material which existed in the solar nebula. Lawrence Grossman has had a most important role in all of these aspects of scientific discovery and understanding. He has combined that blend of inquisitiveness, observation, theory, and measurement which has permitted him to open new doors and to provide deeper understanding.

As an undergraduate at McMaster University he became committed to hard rock geology and went on to graduate school at $Y$ ale University in search of a petrologic problem in an exciting field area. In that intellectually rich and stimulating environment, associated with Karl Turekian and Sidney Clark, he became involved in a rather large field area-the solar nebula. 
Grossman became interested in the type of calculations carried out by Lord and Larimer on the condensation sequence from the hot part of the solar nebula and conceived early some alternatives to that scenario, which led to exciting results. He pursued the theoretical calculations and predicted mineral phases which were quite obviously nonsensical and the source of many chuckles as he reported them to his colleagues and sponsors. But these silly phase assemblages were to be tested against the field area as represented by 2 tons of Allende meteorite, which fell in 1969. From the early reports of Marvin, Wood, and Dickey, it was clear that the peculiar assemblages were realities, and Grossman then turned from a theoretical problem to a combination of theoretical, analytical, and observational work. His study showed in a clear fashion the existence of regular mineralogic relationships that were based on an equilibrium model. These have served as a guide to all subsequent workers in identifying and pursuing early solar system condensates (which are now recognized to represent both equilibrium and, now, nonequilibrium processes).

On the completion of his thesis in 1972 he moved to the University of Chicago, where he has further extended his theoretical, observational, and analytical work on early solar nebular condensates and, in a modest step, has extended his expertise on to condensation in cosmic settings from supernovae. With Clayton and Mayeda, Grossman took part in the fundamental discovery of 160 -rich materials in meteorites. $\mathrm{He}$ has further pursued the mineralogic relationships and their connection with isotopic anomalies. His interest and leadership in the chemistry and the mineralogy of the solar nebula has continued in diverse ways. His Allende field area is very small-comprising $1 / 100$ of a square kilometer (if Allende were all cut up into thin sections), but it is full of unique materials, exhibiting some of the earliest chemical and mineralogic properties known to us. All of us hope that the plethora of 'unique' objects found in this clan of meteorites will lead us toward some golden rules of understanding. We look forward to Larry Grossman's continued exploration of the large from careful and insightful studies of the small.

\section{Gerald J. Wasserburg}

\section{Acceptance}

I want to thank the American Geophysical Union for the great honor which it has bestowed upon me here this evening. There are, however, a great many people and institutions who have had a great influence on my life and career and who, as a result, must share some of the credit for my receiving the Macelwane Award.

It was here in this beautiful city of Toronto where I was born and where my interest in earth science began. I will be forever grateful to my parents for giving me my respect for knowledge and for showing me the treasures to be found in books and libraries. It is thus particularly gratifying to be able to accept this award in my hometown, with my parents present.

My interest in the application of chemical principles to natural processes began with my fascination with the beauty of the crystals in my mineral collection and my awe at how Nature could so efficiently concentrate such rare elements into some of them. My interests in theoretical geochemistry were nurtured by my under-

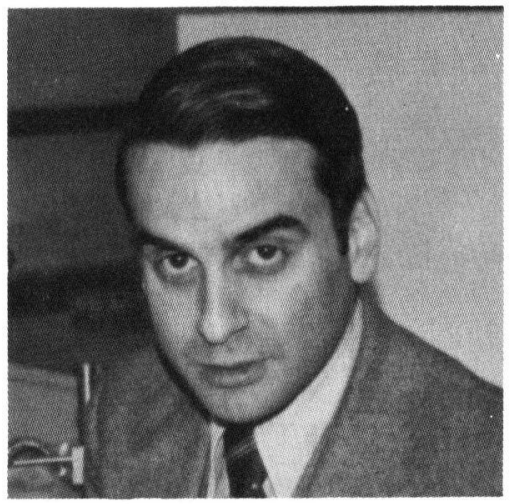

Lawrence Grossman

graduate education at McMaster University in Hamilton, Ontario, not far from here, at a time when other Canadian earth science departments seemed preoccupied with training people in the practical skills required for mineral exploration. It was my thesis adviser at Yale, Karl Turekian, who first inducted me into the mysteries of meteorites and cautioned me that those who studied carbonaceous chondrites worked on holy ground. To those of you who know of Karl's infectious enthusiasm and of the spirit and vitality of his research group, it will be obvious how these stimuli were sufficient to get a student with my background helplessly 'hooked' on meteorites.

Since you have now seen some of Canada, I am sure you can all understand the reasons why I desired so much to return to this country after obtaining my Ph.D. One by one, however, each Canadian university responded to my job applications by saying that they had no position open for someone with my interests. I therefore find it a little sad and ironic that I am being honored tonight in $\mathrm{C}$ anada for my contributions to science which were made in the U.S.A.

Throughout my graduate student years and subsequent period in Chicago, I have been aided greatly by my wife Karen, whose patience, understanding, and strength have been an inspiration to me. As a professor, I encountered an atmosphere at the University of Chicago that encourages independence and the resolute quest for truth, both of which seem to be necessary ingredients for success in this business. Furthermore, that university has a history of considering cosmochemistry to be an important field of inquiry and a tradition of attracting and producing leaders in that branch of science. I owe a great deal to my more senior colleagues at Chicago, particularly Edward Anders and Robert Clayton, for helping me to carry on this tradition. I also thank all those investigators with whom I have had the pleasure of scientific collaboration.

Although it does not seem to be customary to thank funding agencies in acceptance speeches such as this, I feel that I must do so. Without the assistance of the National Aeronautics and Space Administration, much of the research that led me to this platform would have been impossible. To be sure, there were and still are occasional rough times, but without NASA's realization that there is sometimes promise in relatively unknown young investigators, planetary science would not be the highly developed subject which it is today.

My thanks to all of you here tonight. 